\title{
Solventless Acid-Free Synthesis of Mesostructured Titania: Nanovessels for Metal Complexes and Metal Nanoclusters**
}

\author{
By Ömer Dag,* Ivana Soten, Özgür Çelik, Sebastian Polarz, Neil Coombs, and Geoffrey A. Ozin*
}

A new and highly reproducible method to obtain mesostructured titania materials is introduced in this contribution. The mesostructured titania is obtained by employing self-assembled structures of non-ionic alkyl-poly(ethylene oxide) surfactants as templates. The materials are produced without additional solvents such as alcohols, or even water. Only the titanium(Iv) ethoxide and the surfactant $\left(\mathrm{C}_{12} \mathrm{EO}_{10}\right)$ are needed. Water, in the form of that attached to the surfactant and from the atmosphere, induces growth of titania nanoclusters in the synthesis sol. It is indicated that these nanoclusters interact with the surfactant EO-head groups to form a new titanotropic amphiphile. The new amphiphiles self-assemble into titanium nanocluster-surfactant hybrid lyotropic phases, which are transformed to the final mesostructured materials by further condensation of the titania network. The titania materials can be obtained also with noble-metal particles immobilized in the mesostructured framework. It is seen that when different metal salts are used as the metal precursors, different interactions with the titania walls are found. The materials are characterized by X-ray diffraction (XRD), polarization optical microscopy (POM), transmission electron microscopy (TEM), UV-vis spectroscopy, and micro-Raman analysis.

\section{Introduction}

Mesoporous titania currently exists in two forms, ordered mesoporous titania and nanocrystalline titania. Nanocrystalline titania materials are characterized by a random agglomeration of titania nanocrystals in the range of $10-30 \mathrm{~nm}$. Through this type of agglomeration, a disordered porous system in the mesopore-size region is created. Impressive examples of these materials are found in the work of Graetzel and co-workers and others. ${ }^{[1,2]}$ Nanocrystalline titania is finding increasing utility in a number of application areas, including dye-sensitized solar cells, lithium batteries, electrochromic devices, and as catalysts and photocatalysts for environmentally relevant organic oxidation reactions. ${ }^{[3-7]}$ It is the high surface area, surface Lewis and Brønsted acidity and basicity, semiconductor characteristics, and redox flexibility that often make nanocrystalline titania the material of choice for these types of applications. ${ }^{[8-10]}$

Even higher surface areas and much more uniform and controllable pore sizes and pore morphologies are achieved for mesoporous titania. ${ }^{[11-13]}$ This inspires experiments aimed at establishing the electrochemical, photoelectrochemical, and (photo)catalytic properties of titania in its mesoporous state,

[*] Prof. Ö. Dag, Ö. Çelik

Department of Chemistry, Bilkent University

06533 Ankara (Turkey)

dag@fen.bilkent.edu.tr

[*] Prof. G. A. Ozin, Dr. I. Soten, Dr. S. Polarz, Dr. N. Coombs

Materials Chemistry Research Group, Chemistry Department

University of Toronto

80 St. George Street, Toronto, Ontario M5S 3H6 (Canada) gozin@chem.utoronto.ca

[**] GAO is Government of Canada Research Chair in Materials Chemistry. $\mathrm{He}$ is deeply indebted to the Natural Sciences and Engineering Research Council for financial support of this work. ÖD gratefully acknowledge the Scientific and Technical Research Council of Turkey (TÜBİTAK) for financial support of this work under Project TBAG-1812 as well as Bilkent University for a Faculty Development grant. and comparisons of the results to nanocrystalline titania with a view to replacing them in some applications.

Since the first report of mesoporous titania, ${ }^{[14]}$ prepared by the well-documented surfactant templating strategy, ${ }^{[11,12]}$ there has been a great deal of effort devoted to the use of different titania precursors (e.g., alkoxides, halides, acetylacetonates, nanoclusters, colloids) in the synthesis and experiments designed to unravel the structure, property, and function relations of this material. ${ }^{[15,16]}$ Little work has been devoted to understanding the mode of formation of mesoporous titania ${ }^{[17-19]}$ and elucidating the differences with respect to nanocrystalline titania. Much work has also been devoted to ways of templating mesoporous titania with supramolecular assemblies, based on surfactants and amphiphilic block-copolymers. ${ }^{[20,21]}$ This is particularly true with respect to the synthetic challenges associated with the choice of, and command over, the reactivity and assembly of titania precursors, ${ }^{[14,19,22-25]}$ control of the formation of the framework as either the amorphous or nanocrystalline titania phase, and developing successful ways of removing the surfactant from the as-synthesized material while maintaining the integrity of the mesostructure intact.

Reproducibility in obtaining good mesoporous materials for these reported preparations is still a weak point in many cases, as experiments in our laboratory reveal. Therefore, highly reproducible synthetic pathways towards mesoporous titania are still highly desired. To fulfill these goals, a detailed knowledge about the mechanism of formation for these materials is required.

Herein we report a novel solventless acid-free synthesis of surfactant-templated mesoporous titania in the form of monolith and film samples, which are shown to function as nanocontainers for housing metal complexes in a sufficiently stable form for their transformation therein to metal nanoclusters. Further, we investigate mechanistic details in the formation of these mesostructured titania materials. 


\section{Results and Discussion}

This new method for making mesostructured titania involves making an isotropic mixture of tetraethoxyorthotitanate $\mathrm{Ti}(\mathrm{OEt})_{4}$ and a non-ionic surfactant $\mathrm{CH}_{3}\left(\mathrm{CH}_{2}\right)_{n}\left(\mathrm{OCH}_{2} \mathrm{CH}_{2}\right)_{m^{-}}$ $\mathrm{OH}$ that may be spread on a glass slide or contained within a glass vessel. On allowing this mixture to stand in air at room temperature for a period of time, it slowly absorbs atmospheric moisture and spontaneously organizes into the wormhole structure of mesostructured titania as a film or monolith sample, depending on whether it is on a glass slide or in a vessel. In essence, the $\mathrm{Ti}(\mathrm{OEt})_{4}$ precursor behaves much like a "solvent mimic", in that it is able to dissolve the non-ionic surfactant $\mathrm{CH}_{3}\left(\mathrm{CH}_{2}\right)_{n}\left(\mathrm{OCH}_{2} \mathrm{CH}_{2}\right)_{m} \mathrm{OH}$ to form a clear and colorless homogeneous solution. The addition of solvents, as needed in all other reported approaches toward mesostructured titania, is not necessary in this new method. An analysis of the results presented herein for this intriguing mesostructured titania selfassembly process shows that under the chosen synthesis conditions, titanium oxohydroxo alkoxide nanocluster species (denoted $\left.\mathrm{Ti}_{w} \mathrm{O}_{x}(\mathrm{OH})_{y}(\mathrm{OEt})_{z}\right)$ nucleate and grow, co-assemble with the non-ionic surfactants, and undergo hydrolytic polycondensation to create mesostructured titania with a wormhole structure, a uniform pore-size distribution, and an amorphous framework.

At first the materials were investigated by powder X-ray diffraction (PRXD), as shown in Figure 1, and transmission electron microscopy (TEM). The XRD pattern shows a distinct diffraction pattern in the low angle region at $2 \theta=2^{\circ}$, typical for mesostructured samples (see Fig. 1a). In the perspective of classical X-ray crystallography, which is not fully applicable to "worm-hole"-type materials, this scattering angle corresponds to a $d$-spacing of ca. $4.5 \mathrm{~nm}$. As a good approximation, this distance can be interpreted as the center-to-center inter-pore distance. Higher-order diffractions cannot be observed, indicating a "worm-hole"-type material. The findings from the XRD analysis are supported by TEM analysis, which reveals a bicontinuous, interconnected, highly curved pore system, with an average pore diameter of ca. $3 \mathrm{~nm}$ (Fig. 1c). Interestingly, at higher scattering angles (Fig. 1a), a broad diffraction pattern at $2 \theta \approx 8.7^{\circ}$ appears. Our investigations show that the latter scattering pattern is caused by the formation of titania nanoclusters. The mixture of $\mathrm{Ti}_{w} \mathrm{O}_{x}(\mathrm{OH})_{y}(\mathrm{OEt})_{z}$ nanoclusters are ordered well enough to give well-defined X-ray diffraction patterns. The XRD patterns can be understood in the following way. We assume that in the initial stages of this preparation $\approx 1 \mathrm{~nm}$ titania nanoclusters are formed. Via the lyotropic organization by the surfactants, these nanoclusters are spatially distributed into a well-defined periodic array. The nanoclusters are separated by $\approx 1 \mathrm{~nm}$ in these assemblies of nanoclusters, which causes the diffraction pattern around $8.7^{\circ}$. This assumption is in good agreement with the literature, where the presence of an arrangement of germanium sulfide nanoclusters displayed a similar behavior. ${ }^{[26-31]}$

It is also important to note that the mixtures of $\mathrm{Ti}(\mathrm{OEt})_{4} /$ EtOH or $\mathrm{Ti}(\mathrm{OEt})_{4} / \mathrm{EtOH} / \mathrm{C}_{12} \mathrm{EO}_{10}$ produce bigger crystallites a)
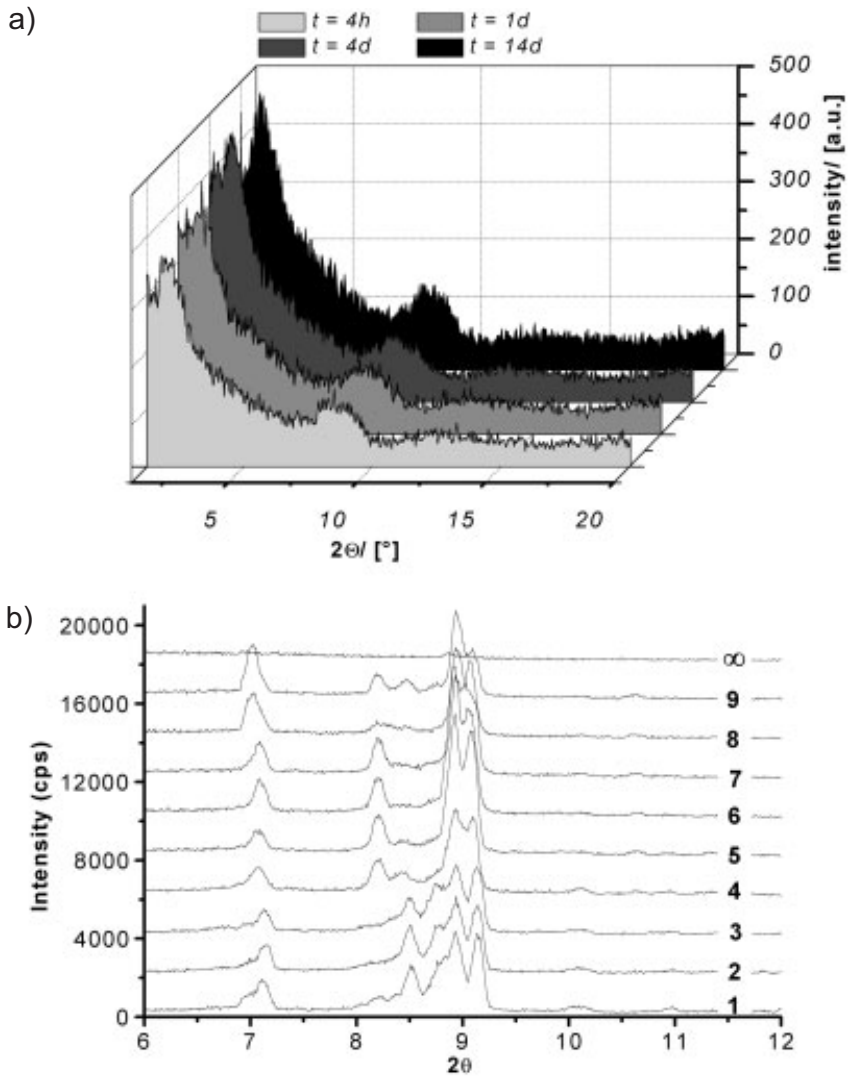

c)

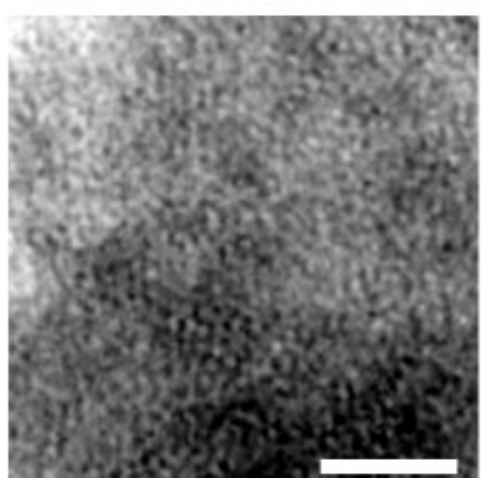

Fig. 1. Time evolution of the PXRD patterns of mesostructured $\mathrm{Ti}_{w} \mathrm{O}_{x}$ $(\mathrm{OH})_{y}(\mathrm{OEt})_{z}$, showing the transformation of the titania nanoclusters into amorphous titania. a) Measurements for the as prepared materials. b) The scattering patterns for the titania nanoclusters grown in a closed container protected from atmospheric humidity. The wide-angle region is recorded every $15 \min$ for $t_{1-9}$ and then, after the container was opened and the sol was exposed to air and equilibrated $\left(t_{\infty}\right)$. c) TEM images for the obtained ordered mesostructured titania materials. The scale bar is $50 \mathrm{~nm}$.

of nanoclusters in a closed container over time. The rate of formation of the $\mathrm{Ti}_{w} \mathrm{O}_{x}(\mathrm{OH})_{y}(\mathrm{OEt})_{z}$ crystallites depends strongly on the amount of water present in the above mixtures. The nanoclusters obtained from both solutions undergo further hydrolysis to yield amorphous titania when exposed to air over time (see Fig. 1b). When we compare the two sets of diffraction patterns (Fig. 1a and 1b), it is clear that the broad peak at around $8.7^{\circ}$ is due to small crystallites or aggregates of nanoclusters. 
The nanocluster formation and polycondensation reactions described above were monitored using FT-Raman micro-spectroscopy, ${ }^{[32,33]}$ as shown in Figure 2. These reactions were followed by monitoring the changes associated with the trans-

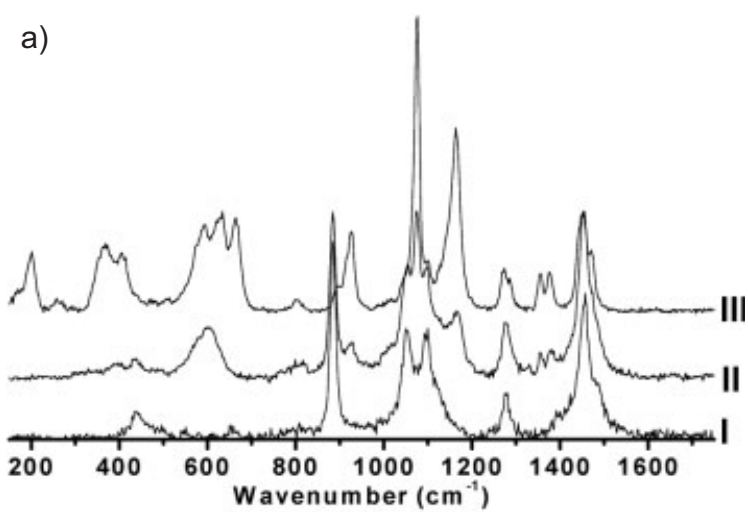

b)

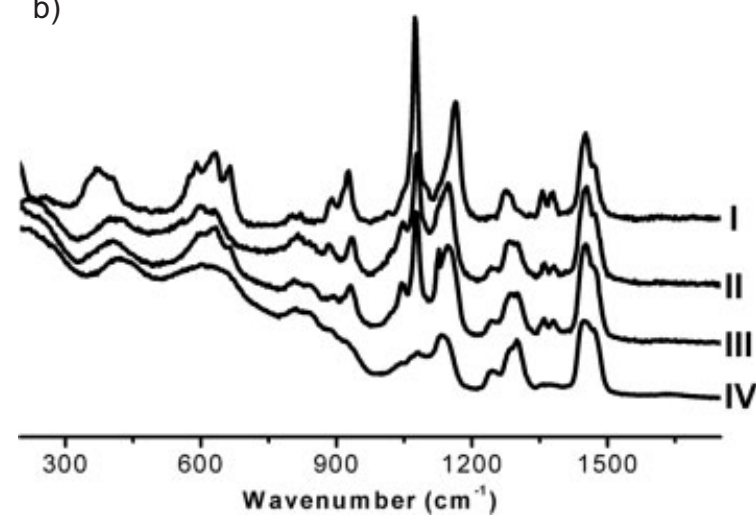

Fig. 2. a) FT-Raman spectra of I) ethanol, II) ethanol and $\mathrm{Ti}\left(\mathrm{OCH}_{2} \mathrm{CH}_{3}\right)_{4}$, and III) $\mathrm{Ti}_{w} \mathrm{O}_{x}(\mathrm{OH})_{y}(\mathrm{OEt})_{z}$ nanoclusters. b) FT-Raman spectra of I) $\mathrm{Ti}_{w} \mathrm{O}_{x^{-}}$ $(\mathrm{OH})_{y}(\mathrm{OEt})_{z}$ nanoclusters, II,III) spectral changes during the hydrolysis of the $\mathrm{Ti}_{w} \mathrm{O}_{x}(\mathrm{OH})_{y}(\mathrm{OEt})_{z}$ nanoclusters, and IV) mesostructured titania product.

formation of nanocluster Raman bands, with narrow line widths, into broadened Raman bands associated with amorphous titania. Figure 2a shows the FT-Raman spectra of ethanol, $\mathrm{Ti}(\mathrm{OEt})_{4}$ in ethanol, and $\mathrm{Ti}_{w} \mathrm{O}_{x}(\mathrm{OH})_{y}(\mathrm{OEt})_{z}$ nanoclusters formed in this solution. The hydrolysis of the $\mathrm{Ti}(\mathrm{OEt})_{4}$ precursor is very fast, and yields $\mathrm{Ti}_{w} \mathrm{O}_{x}(\mathrm{OH})_{y}(\mathrm{OEt})_{z}$ nanoclusters that undergo further polymerization into amorphous titania (Fig. 2b). ${ }^{[34]}$ The formation of titania nanoclusters is in good agreement with the literature. ${ }^{[18,19,35-37]}$ These spectra show how the $\mathrm{Ti}_{w} \mathrm{O}_{x}(\mathrm{OH})_{y}(\mathrm{OEt})_{z}$ nanoclusters ripen after various time periods. The well-resolved diagnostic nanocluster modes in the $500-600,350-450$, and $200-300 \mathrm{~cm}^{-1}$ regions broaden, but their frequencies are maintained almost unaltered with the increasing extent of polymerization. ${ }^{[34]}$ This provides evidence that the $\mathrm{Ti}_{w} \mathrm{O}_{x}(\mathrm{OH})_{y}(\mathrm{OEt})_{z}$ nanoclusters are likely building blocks for the formation of mesostructured titania. Sanchez et al. observed similar behavior in his studies of mesoporous titania by ${ }^{17} \mathrm{O}$ NMR spectroscopy, and we have seen the effects in the Raman spectra for mesostructured titania synthesized from glycometallate surfactants. ${ }^{[23,38]}$ It is also important to note that sharp Raman bands in the spectral region $1000-1200 \mathrm{~cm}^{-1}$ are found to disappear upon polymerization of the $\mathrm{Ti}_{w} \mathrm{O}_{x^{-}}$ $(\mathrm{OH})_{y}(\mathrm{OEt})_{z}$ nanoclusters (Fig. 2b). These peaks are characteristic of ethoxy groups partially covering the surface of the clusters that undergo hydrolysis and condensation to produce Ti-O-Ti or Ti-OH surface species. The broad feature observed around $800-900 \mathrm{~cm}^{-1}$ is most likely due to deformation modes of TiOH sites

One crucial point for the mechanism of formation for this material is whether the titania nanoclusters are formed prior to the formation of the ordered amphiphile domain, simultaneously, or later. Therefore, we performed time-dependent X-ray scattering experiments (see Fig. 1a), and double-checked the results with polarization optical microscopy (POM). After one hour of mixing $\mathrm{Ti}(\mathrm{OEt})_{4}$ and surfactant, the first XRD pattern was recorded (see Fig. 1a). Already in this early stage, the low angle signal $\left(\sim 2^{\circ}\right)$, indicating the formation of a phase with meso-order, is present. Simultaneously, the peak corresponding to the $\mathrm{Ti}_{w} \mathrm{O}_{x}(\mathrm{OH})_{y}(\mathrm{OEt})_{z}$ is present too. With time (1-14 days; samples aged in a controlled humidity box), the meso-peak becomes sharper and slightly more intense and order increases, while the $\mathrm{Ti}_{w} \mathrm{O}_{x}(\mathrm{OH})_{y}(\mathrm{OEt})_{z}$ nanoclusters are still present. Optical birefringence of these samples, found with POM, supports this mechanism. It seems that the formation of the mesophase does not require large amounts of water. From our investigations it is reasonable to assume that the mesophase forms without high water contents, when only the $\mathrm{Ti}_{w} \mathrm{O}_{x^{-}}$ $(\mathrm{OH})_{y}(\mathrm{OEt})_{z}$ clusters are present. The $\mathrm{Ti}_{w} \mathrm{O}_{x}(\mathrm{OH})_{y}(\mathrm{OEt})_{z}$ nanoclusters seem to facilitate the formation of a titania-surfactant mesophase.

In order to provide additional evidence for this assumption, we have performed semi-quantitative molecular-modeling calculations to gain an insight into whether the $\mathrm{Ti}_{w} \mathrm{O}_{x}(\mathrm{OH})_{y^{-}}$ $(\mathrm{OEt})_{z}$ nanoclusters could interact in a certain way with the surfactant. The results of these considerations are shown in Scheme 1. In the first stage of this process, surfactant $\left(\mathrm{C}_{12} \mathrm{EO}_{10}\right)$ is mixed together with $\mathrm{Ti}(\mathrm{OEt})_{4}$. Because we have not dried the surfactant prior to use, some water is present in this solution. We determined gravimetrically that the surfactant contained $1.1 \%$ water. The water induces hydrolysis of the TiOEt bonds, and therefore initiates condensation. Due to this condensation, titania nanoclusters are formed. In order to model the possible interaction between the titania nanocluster and the surfactant, we assumed a hypothetical titania nanocluster that has a size determined in agreement with wide-angle $\mathrm{X}$-ray scattering (WAXS) data, and is crystallographically defined, but is neither rutile nor anatase. All titania atoms are octahedrally coordinated by oxygen. It should be noted that we were not able to determine the true architecture of the titania nanoclusters. The proposed structure is just used as a mimic for the true nanocluster and its surface. We also show images for just the titania nanoclusters having titanol $\mathrm{TiOH}$ groups on the surface. In a separate calculation we also considered ethoxide groups bonded to the surface of the nanoclusters, but this is not described in further detail in this paper because it was found that the surface properties of those nanoclusters do not significantly change upon this substitution. The structure of one exemplary titania nanocluster and a random structure of the 
a)

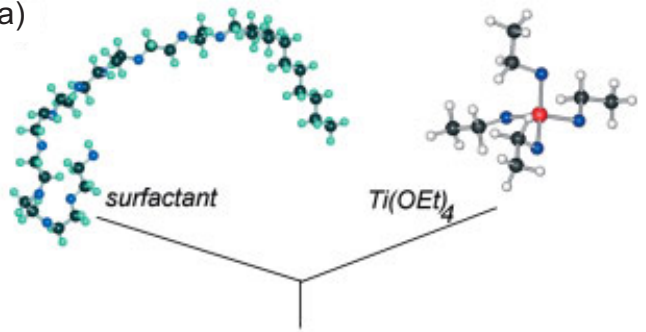

b)

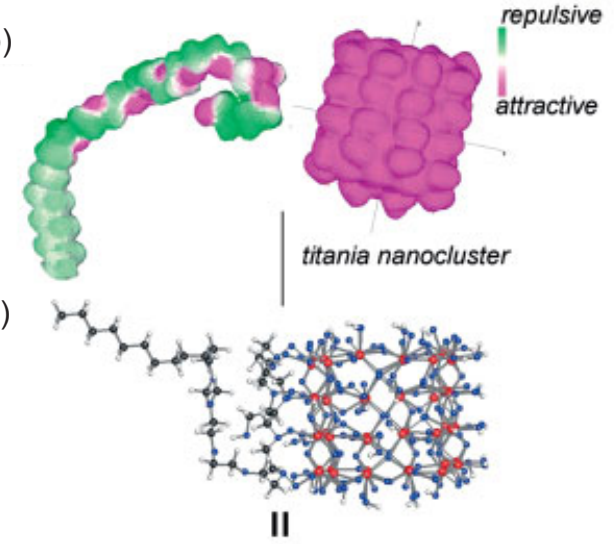

II

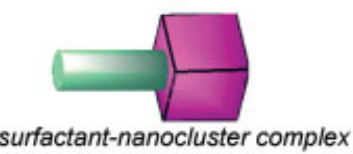

d)

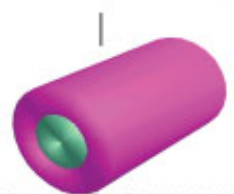

surfactant-nanocluster aggregate

Scheme 1. Schematic representation of the formation mechanism of the mesostructured titania materials presented in this work. The surfactant and titaniumethoxide are mixed. a) Due to surfactant-adsorbed water the formation of titania nanoclusters occurs. b) A hypothetical titania nanocluster and its electrostatic potential surface (color-coded) in comparison to the structure of the surfactant. When the surfactant bonds to the surface of the titania nanocluster, the structure as depicted in (c) is reasonable. In principle, through this surfactant-titania-nanocluster co-assembly a "new" kind of amphiphile is created. In the final step (d), the surfactant-titania-nanocluster complex can self-assemble into ordered surfactant-nanocluster aggregates via microphase separation.

surfactant were optimized using force-field methods (molecular mechanics, MM+ method). The force-field calculations were stopped after 30000 cycles, or when the energy gradient was smaller than $1 \times 10^{-4}$. The geometry was first roughly optimized with a steepest decent algorithm, and finely optimized with a block-diagonal algorithm. This geometry was then taken to perform a semi-empirical single-point calculation using the ZINDO/1 method (intermediate neglect of differential overlap) in order to determine the electrostatic potential surface for the nanocluster and surfactant. Through this method we obtain qualitative understanding of the nature of the interaction. We found that the surfactant, when forming a minimum energy conformation, displays a similar size to the titania cluster, and that the oxygen atoms in the EO-chain of the surfactant create a polar environment. Concerning the electrostatic potential, the surfactant EO-chain fits to the surface of the titania nanocluster (surface-coded in pink). This does not change when eth- oxide groups are bonded to the surface of the nanocluster. Furthermore, the distance between two oxygen atoms in the NEO chain matches almost perfectly the oxygen pattern on the surface of the hypothetical titania nanocluster (see Scheme 1b). Therefore, it was checked by force-field calculations if coordination of titania to these oxygen atoms in the surfactant is possible (see Scheme 1c). From these calculations it seems to be quite favorable for the surfactant to chemisorb on the surface of the titania nanoclusters, a process which also stabilizes this surface. We assume that the surfactant-nanocluster-complex is formed within the formation procedure of our mesostructured titania samples. The titania nanocluster alters the head-group region of the surfactant, and therefore changes the packing parameter. This change in packing parameter could induce the microphase separation that leads to the formation of the mesophase (instead of a worm-hole phase, a cylindrical aggregate is shown) as indicated in Scheme 1c,d.

It is very probable from these considerations that there is indeed an interaction between the $\mathrm{Ti}_{w} \mathrm{O}_{x}(\mathrm{OH})_{y}(\mathrm{OEt})_{z}$ nanoclusters and the surfactant. The proposed mechanism is reasonable since Dag et al. demonstrated that water coordinated to transition metal ions is able to induce, through hydrogen-bonding interactions, self-assembly of non-ionic surfactants to hexagonal and cubic liquid-crystalline phases. ${ }^{[39]}$ Thus it is reasonable that preformed $\mathrm{Ti}_{w} \mathrm{O}_{x}(\mathrm{OH})_{y}(\mathrm{OEt})_{z}$ nanoclusters with their surface hydroxyl groups are similarly able to induce self-assembly of the non-ionic surfactant molecules into a co-assembled "titanotropic" liquid-crystal templating mesophase. Interactions between coordinately unsaturated titanium(IV) surface sites and oxygens of the oligo(ethylene oxide) head group of the nonionic surfactant are also likely to facilitate this co-assembly process. There is a resemblance between this proposed mode of formation of mesostructured titania from a "titanotropic" liquid crystal and the so-called true liquid-crystal templating mechanism of mesostructured silica. In the latter, surface silanol groups on silicate precursors in a preformed "silicatropic" liquid crystal are considered to be responsible for the organization of surfactant molecules into the templating mesophase. ${ }^{[40,41]}$ However, formation of a mesoporous silica in the absence of water or other solvents has not been reported to the best of our knowledge. This reveals the crucial importance of the $\mathrm{Ti}_{w} \mathrm{O}_{x}(\mathrm{OH})_{y}-(\mathrm{OEt})_{z}$ nanocluster-surfactant interactions, which are in the case of silica much weaker, and for the true liquid-crystal mechanism restricted to hydrogen-bonding. Alternatively, the $\mathrm{Ti}_{w} \mathrm{O}_{x}(\mathrm{OH})_{y}(\mathrm{OEt})_{z}$ nanoclusters could act as a hydrophilic solvent mimic, inducing microphase separation of the surfactant. The mechanism we propose here is reported for the first time. When surfactant and $\mathrm{Ti}(\mathrm{OEt})_{4}$ are mixed, the formation of $\mathrm{Ti}_{w} \mathrm{O}_{x}(\mathrm{OH})_{y}(\mathrm{OEt})_{z}$ nanoclusters starts due to residual water in the synthesis mixture. These nanoclusters interact with the surfactant and induce the formation of the mesophase even without water. The surfactant pre-organizes the clusters, which are attached to its head group. There is a certain synergistic element in this mechanism. Interestingly, Ying and co-workers proposed a similar type of interaction between monomeric inorganic oxide precursor species and surfactant head-groups. ${ }^{[42]}$ In their case, either charged surfactants 
were used, leading to electrostatic interactions, or the surfactant is covalently linked to the inorganic precursor. ${ }^{[42]}$ The creation of new amphiphiles connecting surfactants with inorganic clusters is a unique and new method to structure matter as other examples also demonstrate. ${ }^{[43]}$

Finally, when the mesostructure has been established, the $\mathrm{Ti}_{w} \mathrm{O}_{x}(\mathrm{OH})_{y}(\mathrm{OEt})_{z}$ clusters are hydrolyzed by water and the order increases. The final product, a mesostructured form of titania, retains no indications to indicate its quite refined formation process.

The procedure described above is rather well suited to uniformly incorporate metal complexes and metal nanoclusters into mesostructured titania film and monolith samples. It was found that metal complex anions such as, $\mathrm{PtCl}_{6}{ }^{2-}$ and $\mathrm{AuCl}_{4}{ }^{-}$ in the acid form, and $\mathrm{Ag}^{+}$ions in the presence of triflate or nitrate, do not affect the ability of $\mathrm{Ti}(\mathrm{OEt})_{4}$ and the non-ionic surfactant $\mathrm{CH}_{3}\left(\mathrm{CH}_{2}\right)_{n}\left(\mathrm{OCH}_{2} \mathrm{CH}_{2}\right)_{m} \mathrm{OH}$ to either co-assemble, form $\mathrm{Ti}_{w}-\mathrm{O}_{x}(\mathrm{OH})_{y}(\mathrm{OEt})_{z}$ nanoclusters, or hydrolytically polycondense further to the mesostructured titania worm-hole structured material. Dried metal complexes/salts were first dissolved in the minimum amount of ethanol, and then the nonionic surfactant $\mathrm{CH}_{3}\left(\mathrm{CH}_{2}\right)_{n}\left(\mathrm{OCH}_{2} \mathrm{CH}_{2}\right)_{m} \mathrm{OH}$ was introduced. After addition of the $\mathrm{Ti}(\mathrm{OEt})_{4}$ precursor, the reaction mixture was spread on a glass slide or contained within a Teflon boat. Absorption and diffusion of atmospheric water into the reaction mixture occurs as before to hydrolyze and assemble the $\mathrm{Ti}(\mathrm{OEt})_{4}$ precursor with the non-ionic surfactant $\mathrm{CH}_{3}\left(\mathrm{CH}_{2}\right)_{n^{-}}$ $\left(\mathrm{OCH}_{2} \mathrm{CH}_{2}\right)_{m} \mathrm{OH}$, which then proceeds to form the "salted" mesostructured titania samples. The samples prepared in this way diffract X-rays in the low-angle region with a $d$-spacing of about $45-50 \AA$ A. Figure 3 shows representative PXRD patterns for different metal complexes and concentrations. The diffraction patterns of these materials are not very sensitive to changes in the metal/Ti ratio showing at most 3-4 $\AA$ alterations in the $d$-spacing, and are very similar to those of the mesostructured titania obtained in the absence of the metal complexes/ salts. We assume that $\mathrm{AuCl}_{4}^{-}$and $\mathrm{PtCl}_{6}{ }^{2-}$ ions bind to the surface of the $\mathrm{Ti}_{w} \mathrm{O}_{x}(\mathrm{OH})_{y}(\mathrm{OEt})_{z}$ nanoclusters and mesostructured titania through a combination of interactions, including electrostatic, hydrogen-bonding, and surface-coordination, similar to silica chemistry. ${ }^{[4]}$ Note that the $\mathrm{AuCl}_{4}{ }^{-}$and $\mathrm{PtCl}_{6}{ }^{2-}$ ions are quite stable under these reaction conditions, and do not undergo reduction and/or ligand exchange reactions. Also, the $\mathrm{AuCl}_{4}^{-}$and $\mathrm{PtCl}_{6}{ }^{2-}$ anions appear to be strongly held within the mesostructured titania matrix, because they hardly leach out from film and monolith samples after extensive washing with water or ethanol. This is not the case for the $\mathrm{Ag}^{+}$containing samples. Large-area films could be obtained via this method, and a photograph of these samples containing different metal complexes is shown in Figure 4a. The synthesis solution in this process solidifies in about $30 \mathrm{~min}$, but the room-temperature hydrolytic polycondensation reaction appears to continue long after, sometimes for days and weeks.

The FT-Raman spectra of the mesostructured titania materials prepared in the presence of these anionic metal halide complexes displayed diagnostic spectral signatures of $\mathrm{PtCl}_{6}^{2-}$ and $\mathrm{AuCl}_{4}{ }^{-}$anions; however, the samples gradually photo-degraded

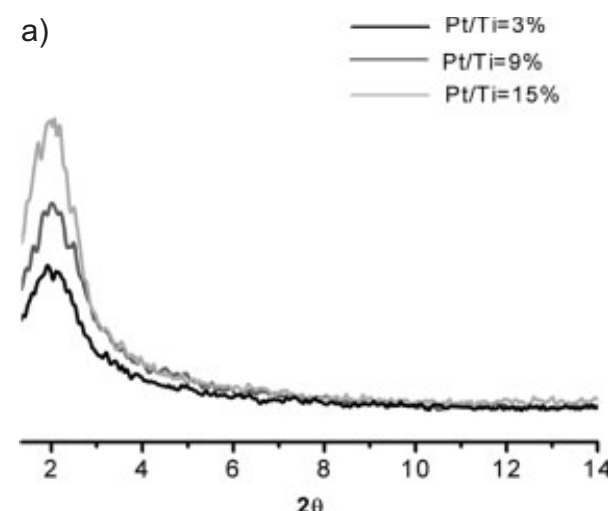

b)

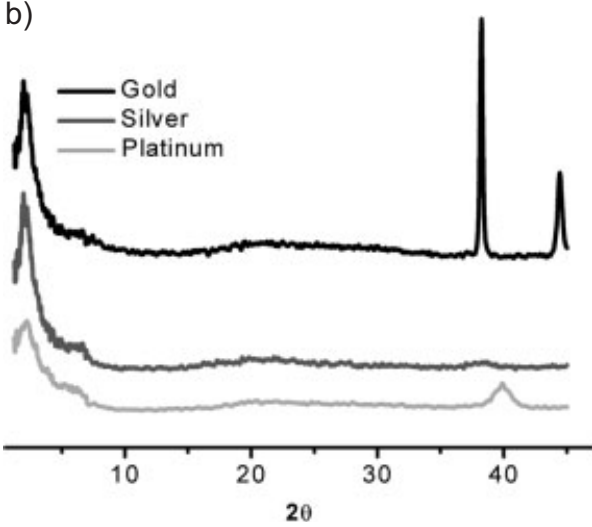

Fig. 3. a) Representative PXRD patterns for meso- $\mathrm{TiO}_{2}-\mathrm{PtCl}_{6}{ }^{2-}$ for different loadings of $\mathrm{H}_{2} \mathrm{PtCl}_{6}$. b) Representative PXRD patterns for meso- $\mathrm{TiO}_{2}-\mathrm{M}_{n}$ (reduced samples) where $\mathrm{M}=\mathrm{Au}, \mathrm{Ag}, \mathrm{Pt}$.

a)

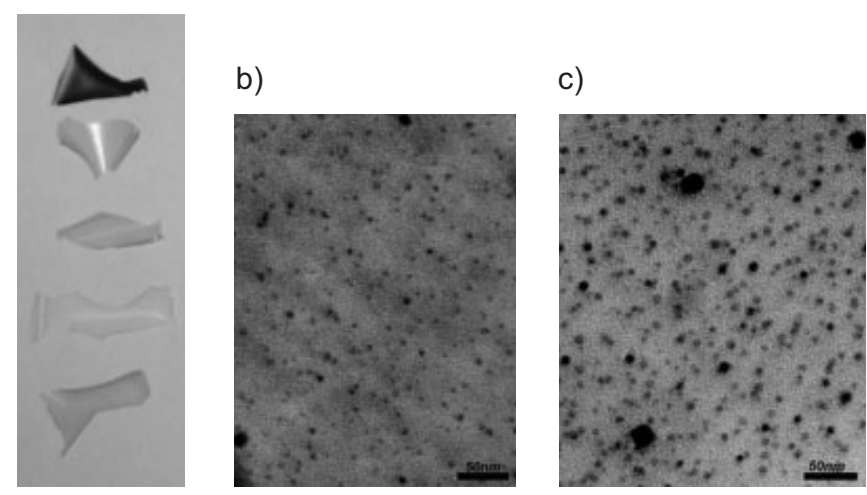

Fig. 4. a) Photographs (bottom to top) of meso- $\mathrm{TiO}_{2}-\mathrm{Ag}^{+}$(sand color), meso$\mathrm{TiO}_{2}$ (colorless), meso- $\mathrm{TiO}_{2}-\mathrm{AuCl}_{4}^{-}$(yellow), meso- $\mathrm{TiO}_{2}-\mathrm{PtCl}_{6}{ }^{2-}$ (light red) and meso- $\mathrm{TiO}_{2}-\mathrm{Pt}_{n}$ (brown-black). b,c) TEM images of meso- $\mathrm{TiO}_{2}-\mathrm{Ag}_{n}$ synthesized with $\mathrm{Ag}^{+} /$surfactant mole ratios of 0.35 (right) and 0.19 (left).

in the laser beam. The UV-vis absorption spectra of these samples also showed the characteristic $\mathrm{d}-\mathrm{d}$ and charge-transfer electronic transitions of $\mathrm{PtCl}_{6}{ }^{2-}$ and $\mathrm{AuCl}_{4}{ }_{4}^{-}$ions. It is likely that these anionic metal complexes interact with the surface of the mesostructured titania framework through electrostatic forces, as well as halide coordination and hydrogen bonding to $\mathrm{Ti}^{\mathrm{IV}}$ and $\mathrm{TiOH}$ sites, respectively. Interactions of this type provide an opportunity to reduce the anionic metal halide complexes within the mesopores of the titania framework, to create en- 
capsulated nanoclusters of platinum and gold with a narrow size distribution enforced by the spatial confinement of the redox induced aggregation process. It is important to note that $\mathrm{PtCl}_{6}{ }^{2-}$ and $\mathrm{AuCl}_{4}{ }^{-}$complexes are stable to the synthesis conditions used to make the mesostructured titania, and that reduction of these complexes is induced intentionally by exposing the as-synthesized meso- $\mathrm{TiO}_{2}-\mathrm{PtCl}_{6}{ }^{2-} / \mathrm{AuCl}_{4}{ }^{-}$nanocomposite to the appropriate reducing agent (in these studies, hydrogen or hydrazine). Therefore, by using this co-assembly strategy, $\mathrm{PtCl}_{6}{ }^{2-}$ or $\mathrm{AuCl}_{4}{ }^{-}$metal complexes are initially uniformly distributed within the $\mathrm{Ti}_{w} \mathrm{O}_{x}(\mathrm{OH})_{y}(\mathrm{OEt})_{z}$ nanocluster/non-ionic surfactant mesophase that undergoes hydrolytic polycondensation to form the meso- $\mathrm{TiO}_{2}-\mathrm{PtCl}_{6}{ }^{2-} / \mathrm{AuCl}_{4}{ }^{-}$nanocomposite as a film or monolith. Reduction of the metal complexes housed within the nanoreaction vessels of the mesostructured titania host was carried out under flowing $\mathrm{H}_{2}$ in the temperature range $100-200{ }^{\circ} \mathrm{C}$. The platinum samples undergo reduction very quickly under $\mathrm{H}_{2}$ at $100{ }^{\circ} \mathrm{C}$. The reduction temperature for the gold samples was $200^{\circ} \mathrm{C}$. The low angle PXRD patterns show a single diffraction line in the $1.5-2.0^{\circ} 2 \theta$ region for all of the samples, including the silver-containing ones (Fig. 3b). The sharp low-angle peaks $\left(2 \theta \approx 2^{\circ}\right)$ typical for the mesostructure is also apparent in Figure $3 \mathrm{~b}$ for all samples. The high-angle PXRD region shows broad lines corresponding to the (111) and (200) reflections of the metal nanoclusters for $\mathrm{Pt}$ and $\mathrm{Ag}$. For Au however, much sharper reflections indicate larger particle sizes (see Table 1). The calculated sizes of these nanoclusters, obtained by applying the Scherrer equation to these broad

Table 1.

\begin{tabular}{cccc}
\hline $\begin{array}{c}\text { Metal } \\
\text { nanoparticle }\end{array}$ & $\begin{array}{c}\text { Metal/Ti ratio } \\
{[\%]}\end{array}$ & $\begin{array}{c}\text { Metal particle } \\
\text { size (PXRD) } \\
{[\mathrm{nm}]}\end{array}$ & $\begin{array}{c}\text { Metal particle } \\
\text { size (TEM) } \\
{[\mathrm{nm}]}\end{array}$ \\
\hline $\mathrm{Pt}$ & 15 & 6.2 & N/A \\
$\mathrm{Pt}$ & 10 & $\mathrm{~N} / \mathrm{A}$ & 2.5 \\
$\mathrm{Pt}$ & 3 & 6.4 & 6.2 \\
$\mathrm{Ag}$ & 55 & 5.6 & N/A \\
$\mathrm{Ag}$ & 34 & 6.4 & 5.8 \\
$\mathrm{Ag}$ & 24 & $\mathrm{~N} / \mathrm{A}$ & 4 \\
$\mathrm{Ag}$ & 19 & $\mathrm{~N} / \mathrm{A}$ & 3.7 \\
$\mathrm{Au}, \mathrm{H}_{2}$ & 37 & 13.1 & N/A \\
$\mathrm{Au}, \mathrm{H}_{2}$ & 26 & 37.3 & 33.5 \\
$\mathrm{Au}, \mathrm{H}_{2}$ & 16 & 43.3 & N/A \\
$\mathrm{Au}, \mathrm{H}_{2}$ & 8.5 & 30 & N/A \\
$\mathrm{Au}, \mathrm{N}_{2} \mathrm{H}_{4}$ & 37 & 20.5 & N/A \\
$\mathrm{Au}, \mathrm{N}_{2} \mathrm{H}_{4}$ & 29 & 17.2 & N/A \\
$\mathrm{Au}, \mathrm{N}_{2} \mathrm{H}_{4}$ & 12 & 14.1 & 12 \\
\hline
\end{tabular}

PXRD lines, are found to be consistent with the measured sizes of the nanoclusters from the TEM images (Table 1 and Fig. 4). When the nanoclusters were too small to display high-angle diffraction lines, the nanocluster sizes listed in Table 1 were obtained from the TEM measurements. This underlines that the addition of salts does not disturb the meso-formation of the materials.

The structure of meso- $\mathrm{TiO}_{2}-\mathrm{M}_{n}$ nanocomposites, prepared using the procedure described in this study, typically comprises a fairly uniform and narrow size distribution of metal nanoclusters, housed within a mesostructured titania wormhole matrix
(Fig. 4c). Representative TEM images obtained for two different concentrations of the silver samples, show silver nanoclusters with sizes in the range $3-5 \mathrm{~nm}$. Similar images were obtained for gold and platinum metal nanoclusters, but with slightly larger sizes. UV-vis-NIR diffuse-reflectance spectra of the silver and gold samples display diagnostic broad ultraviolet and visible features, respectively, which are associated with the plasmon resonance of conduction electrons in the metal nanoclusters. In the case of the samples containing platinum nanoclusters, the reflectance spectrum displays a broad feature across the entire spectral range. Besides these small metal particles, a few having larger sizes (ca. $10 \mathrm{~nm}$ ) can be detected via TEM.

\section{Conclusion}

The results of this investigation demonstrate that non-ionic surfactants, $\mathrm{CH}_{3}\left(\mathrm{CH}_{2}\right)_{n}\left(\mathrm{OCH}_{2} \mathrm{CH}_{2}\right)_{m} \mathrm{OH}$, dissolve in tetraethoxyorthotitanate $\mathrm{Ti}(\mathrm{OEt})_{4}$ to form an isotropic solution. This solution can be spread on a glass substrate or held within a glass container, slowly absorbs atmospheric moisture, and spontaneously organizes into the worm-hole structure of mesostructured titania as a film or monolith, respectively (depending on whether it is on a substrate or within a container), when permitted to stand in air at room temperature for a period of time (see Fig. 4a). A co-assembly model is proposed for the formation of mesostructured titania under these synthesis conditions. This model is based upon the controlled hydrolysis of $\mathrm{Ti}(\mathrm{OEt})_{4}$ in the presence of $\mathrm{CH}_{3}\left(\mathrm{CH}_{2}\right)_{n}\left(\mathrm{OCH}_{2} \mathrm{CH}_{2}\right)_{m} \mathrm{OH}$ to create a $\mathrm{Ti}_{w} \mathrm{O}_{x}(\mathrm{OH})_{y}(\mathrm{OEt})_{z}$ nanocluster/non-ionic surfactant "titanotropic" mesophase that undergoes hydrolytic polycondensation to give mesostructured titania with a wormhole structure, a uniform pore size distribution, and an amorphous titania framework. By calcination of these surfactant-containing mesostructured titania materials, mesoporous versions are obtained, but the pore structure has not yet been characterized by sorption methods. It is seen that calcination alters the XRD patterns insignificantly, and the wormhole pore structure is still apparent in TEM investigations. The titania network itself remains amorphous even after calcination at $450{ }^{\circ} \mathrm{C}$. It is also found that $\mathrm{PtCl}_{6}{ }^{2-}, \mathrm{AuCl}_{4}^{-}$, and $\mathrm{Ag}^{+}$ions do not disturb the formation of the $\mathrm{Ti}_{w} \mathrm{O}_{x}(\mathrm{OH})_{y}(\mathrm{OEt})_{z}$ nanocluster/non-ionic surfactant mesophase, which enables them to be uniformly integrated into the mesostructured titania matrix, and subsequently reduced therein to metal nanoclusters. This method produces meso- $\mathrm{TiO}_{2}-\mathrm{M}_{n}$ nanocomposite film and monolith samples, containing a fairly narrow size distribution of metal nanoclusters, which might find utility as selective oxidation catalysts and active photo-oxidation catalysts in a range of green chemistry applications.

\section{Experimental}

Materials Synthesis: The pure phase was prepared using various ratios of the surfactant, $\mathrm{C}_{12} \mathrm{EO}_{10}$ and the titania source, $\mathrm{Ti}(\mathrm{OEt})_{4}$ to optimize the reaction conditions. It was discovered that the best result is obtained if the $\mathrm{Ti}(\mathrm{OEt})_{4} /$ surfactant mole ratio is around 5:1. In a typical synthesis $1.0 \mathrm{~g}$ of $\mathrm{C}_{12} \mathrm{EO}_{10}$ was mixed 
with $1.80 \mathrm{~g}$ of $\mathrm{Ti}(\mathrm{OEt})_{4}$. The mixture is quite fluid and can be spread on a glass slide (or any other substrate) for the controlled hydrolysis step. In a short time, the mixture thickens and gradually forms an anisotropic solid film or monolith The $\mathrm{Ag}^{+}, \mathrm{AuCl}_{4}^{-}$, and $\mathrm{PtCl}_{6}{ }^{2-}$ ion containing samples were prepared by dissolving 0.1-0.22 $\mathrm{g} \mathrm{AgCF}_{3} \mathrm{SO}_{3}, 0.1-0.44 \mathrm{~g} \mathrm{HAuCl}_{4}$, and $0.1-0.50 \mathrm{~g} \mathrm{H}_{2} \mathrm{PtCl}_{6}$ salt or acids in a minimum amount of ethanol, respectively. To the above solution, $1.0 \mathrm{~g}$ surfactant and $1.80 \mathrm{~g} \mathrm{Ti}(\mathrm{OEt})_{4}$ were added to obtain a clear solution. This solution was then exposed to air in the dark to obtain homogenously mixed $\mathrm{Ag}^{+}, \mathrm{AuCl}_{4}{ }^{-}$, and $\mathrm{PtCl}_{6}{ }^{2-}$ ions containing mesostructured titania materials. All the samples were kept in the dark under laboratory conditions for several days before analysis and the reduction processes.

Characterization Methods: Polarization optical microscopy (POM) images were recorded in transmission mode on an Olympus BH-2 microscope using convergent white light between parallel and crossed polarizers. The PXRD patterns were obtained on a Siemens D5000 diffractometer using a high-power $\mathrm{Cu} \mathrm{K \alpha}$ source operating at $50 \mathrm{kV}$ and $35 \mathrm{~mA}$ and/or a Rigaku Miniflex diffractometer using a high power $\mathrm{Cu} \mathrm{K} \alpha$ source operating at $30 \mathrm{kV}$ and $15 \mathrm{~mA}$. The TEM images were obtained using a Philips 430 microscope operating at an acceleration voltage of $100 \mathrm{kV}$. The samples were embedded in epoxy resin and microtomed. The micro-Raman spectra were obtained on an S. A. LabRam confocal Raman microscope. The signal collected was transmitted through a fiber optic cable into a single grating spectrometer equipped with a $1024 \times 256$ element CCD. The Raman spectra were collected by manually placing the probe tip near the desired point of the film. The UV-vis absorption spectra were recorded in diffuse reflectance mode using a Perkin Elmer double-beam spectrometer.

Received: July 3, 2002 Final version: August 21, 2002

[1] B. Oregan, M. Graetzel, Nature 1991, 353, 737.

[2] U. Bach, D. Lupo, P. Comte, J. E. Moser, F. Weissortel, J. Salbeck, H. Spreitzer, M. Graetzel, Nature 1998, 395, 583 .

[3] H. L. Tuller, Solid State Ionics 2000, 131, 143.

[4] M. Graetzel, Curr. Opin. Colloid Interface Sci. 1999, 4, 314

[5] A. Chemseddine, T. Moritz, Eur. J. Inorg. Chem. 1999, 235.

[6] Z. B. Zhang, C. C. Wang, R. Zakaria, J. Y. Ying, J. Phys. Chem.B 1998, 102 , 10871 .

[7] U. Trudinger, G. Mueller, K. K. Unger, J. Chromatogr. 1990, 535, 111.

[8] I. Soten, G. A. Ozin, Curr. Opin. Colloid Interface Sci. 1999, 4, 325.

[9] I. Soten, G. A. Ozin, in Supramolecular Materials Design, Cambridge University Press, Cambridge, UK 2002, p. 34.

[10] G. A. Ozin, Chem. Commun. 2000, 419.

[11] F. Schueth, Chem. Mater. 2001, 13, 3184.

[12] T. J. Barton, L. M. Bull, W. G. Klemperer, D. A. Loy, B. McEnaney, M. Misono, P. A. Monson, G. Pez, G. W. Scherer, J. C. Vartuli, O. M. Yaghi, Chem. Mater. 1999, 11, 2633.

[13] P. Yang, D. Zhao, D. I. Margolese, B. F. Chmelka, G. D. Stucky, Nature 1998, 396, 152.
[14] D. M. Antonelli, J. Y. Ying, Angew. Chem. Int. Ed. Engl. 1995, 34, 2014

[15] H. Yoshitake, T. Sugihara, T. Tatsumi, Chem. Mater. 2002, 14, 1023

[16] Y. Q. Wang, X. H. Tang, L. X. Yin, W. P. Huang, Y. R. Hacohen, A. Gedanken, Adv. Mater. 2000, 12, 1183

[17] F. Ribot, C. Sanchez, Comments Inorg. Chem. 1999, 20, 327.

[18] G. Soler-Illia, E. Scolan, A. Louis, P. A. Albouy, C. Sanchez, New J. Chem 2001, 25, 156 .

[19] E. Scolan, C. Magnenet, D. Massiot, C. Sanchez, J. Mater. Chem. 1999, 9, 2467.

[20] P. D. Yang, D. Y. Zhao, D. I. Margolese, B. F. Chmelka, G. D. Stucky, Chem. Mater. 1999, 11, 2813.

[21] L. Kavan, J. Rathousky, M. Graetzel, V. Shklover, A. Zukal, Microporous Mesoporous Mater. 2001, 44, 653.

[22] H. S. Yun, K. Miyazawa, H. S. Zhou, I. Honma, M. Kuwabara, Adv. Mater 2001, 13, 1377.

[23] D. Khushalani, Ö. Dag, G. A. Ozin, A. Kuperman, J. Mater. Chem. 1999, 9 , 2715.

[24] Y. K. Hwang, K. C. Lee, Y. U. Kwon, Chem. Commun. 2001, 1738

[25] D. Grosso, G. Soler-Illia, F. Babonneau, C. Sanchez, P. A. Albouy, A. Brunet-Bruneau, A. R. Balkenende, Adv. Mater. 2001, 13, 1085.

[26] P. N. Trikalitis, K. K. Rangan, M. G. Kanatzidis, J. Am. Chem. Soc. 2002 124,2604

[27] K. K. Rangan, P. N. Trikalitis, T. Bakas, M. G. Kanatzidis, Chem. Commun 2001, 809.

[28] P. N. Trikalitis, K. K. Rangan, T. Bakas, M. G. Kanatzidis, Nature 2001, 410, 671.

[29] K. K. Rangan, P. N. Trikalitis, M. G. Kanatzidis, J. Am. Chem. Soc. 2000, 122, 10230 .

[30] M. Wachhold, K. K. Rangan, M. Lei, M. F. Thorpe, S. J. L. Billinge, V. Petkov, J. Heising, M. G. Kanatzidis, J. Solid State Chem. 2000, 152, 21.

[31] M. Wachhold, K. K. Rangan, S. J. L. Billinge, V. Petkov, J. Heising, M. G Kanatzidis, Adv. Mater. 2000, 12,85

[32] P. A. Venz, R. L. Frost, J. R. Bartlett, J. L. Woolfrey, Spectrochim. Acto Part $A$ 1997, 53, 969.

[33] J. M. Miller, L. J. Lakshmi, J. Phys. Chem. B 1998, 102, 6465.

[34] P. J. Huang, H. Chang, C. T. Yeh, C. W. Tsai, Thermochim. Acta 1997, 297,

[35] G. Soler-Illia, L. Rozes, M. K. Boggiano, C. Sanchez, C. O. Turrin, A. M. Caminade, J. P. Majoral, Angew. Chem. Int. Ed. 2000, 39, 4250.

[36] V. W. Day, T. A. Eberspacher, W. G. Klemperer, C. W. Park, J. Am. Chem Soc. 1993, 115, 8469 .

[37] R. Schmid, A. Mosset, J. Galy, J. Chem. Soc., Dalton Trans. 1991, 1999.

[38] D. Khushalani, G. A. Ozin, A. Kuperman, J. Mater. Chem. 1999, 9, 1491.

[39] Ö. Celik, Ö. Dag, Angew. Chem. Int. Ed. 2001, 40, 3800.

[40] G. S. Attard, J. G. Glyde, C. G. Goeltner, Nature 1995, 378, 366

[41] C. G. Goeltner, M. Antonietti, Adv. Mater. 1997, 9, 431.

[42] D. M. Antonelli, A. Nakahira, J. Y. Ying, Inorg. Chem. 1996, 35, 3126.

[43] S. Polarz, B. Smarsly, M. Antonietti, ChemPhysChem 2001, 2, 457.

[44] L. M. Bronstein, S. Polarz, B. Smarsly, M. Antonietti, Adv. Mater. 2001, 13, 1333. 